\title{
ISSUES CHALLENGING UNIVERSITIES: A CASE OF TANZANIAN HIGHER EDUCATION
}

\author{
Yeni Murdani Istoroyekti, S.S., M.Hum. \\ yenimurdani@gmail.com \\ STKIP Surya
}

\begin{abstract}
For the last decade, Tanzania has suffered setback on number of unemployed graduate. The majority, to certain extent, put on the responsibility to higher institutions because it does not equip graduates with sufficient skills suitable for job demand. This paper highlights the root of such issues, deriving from my experience during three-year teaching assignment in Tanzania. The observation and reviewed on relevant literature revealed that the problem is a result of an ongoing mismanaged education system, starting from lower level of education, and partly the responsible government bodies. Improvements on the system and breakthrough action are salient to provide qualified graduates as the market demands.
\end{abstract}

Keywords: higher education, education system, university graduate

\section{INTRODUCTION}

It has been more than two decades that Tanzania and Africa in general (excluding South Africa) have suffered setback in high education. As mentioned in the World Bank report 2004, Tanzania is among the countries that receives major lay back in education and among the reasons is financial problem; World Bank mentions that Tanzania is the third country receiving the biggest financial donor from abroad. The report also mentions that university enrolment in Tanzania is very low compared to other developing countries and is very low if compared to the neighboring countries in the East African community.

The rapid growth of higher education institution is not accompanied by sufficient number of students' enrollment; even though government has made is easy for Tanzanian to access it. In Education for Self-reliance, Julius Nyerere mentions that the purpose of education in Tanzania is "[It must] encourage the development of proud, independent and free citizenry which relies upon itself for its own development, and which knows the advantages and the problems of co-operation" (Nyerere, 1967). His notion on education promotes the importance of able and capable human resources as well as constructive and productive agents in society. In other words, Nyerere addresses university as the manufacturer of high qualified people who are of beneficial for his/her community and to develop it. 
Looking back at Tanzania's higher education history, since her independence and her union with Zanzibar, Tanzania has made rapid progress in term of higher education system, from one university in the 1970 s to more than 40 universities in 2014 (both public and private universities). This massive progress in one hand provides Tanzanian accessible higher education but in other hand it places quality education at stake. The issue of human capital, facilities, and credibility has been challenging across Tanzania, both public and private universities and in the long run it jeopardizes the higher education system itself.

Reviewing related literatures, current education system and major problem facing Tanzania today, it is important to revise and promote a liberating education system that train students to be independent, critical and analytical. This paper aims is to examine challenges faced by higher education in Tanzania and to approach such challenges using secondary data sources. Using St. Augustine University of Tanzania (SAUT) as starting point and contextualize it into broader scope, the data was mainly gathered from unstructured interview with both students and academic staffs in the mentioned university. As this is also a descriptive paper, reviewed on literature especially daily papers are very significant to widen the perspective on the situation of higher education in Tanzania. Hence, the case in St. Augustine University of Tanzania extends to national scope.

\section{TANZANIA: FACTS AND FIGURES}

Tanzania is located in the eastern part of Africa and becomes a member of Eastern Africa Community along with Uganda, Kenya, Rwanda, and Burundi with population 49.25 million in 2013 . The country covers $945,203 \mathrm{~km}^{2}$ with the economic capital Dar es Salaam, located at the coast of Indian Ocean, and political capital is in Dodoma located in the center of Tanzania. The country consists of 30 administrative regions: 5 regions are in Zanzibar Island and 25 are in Tanzania mainland; Tanzania derives its name from Tanganyika and Zanzibar that merged in 1964. After British colonial left, Tanzania adopted socialism under Julius Nyerere, the first president.

Economically, Tanzania is among the poorest countries that rely on foreign donor. According to World Bank and UNDP website, Tanzania is among the low income countries with poverty lines approximately $28.2 \%$ and average per capita income is between $\$ 500-1000$. The youth labor force grows each year by 800,000 unparallel with the job market availability.

As many Africa new states suffered of tribal war, the first president, Julius Nyerere, created sense of unity among diverse ethnic groups in Tanzania. Hence, Swahili is promoted as the national language among ethnic groups to avoid tribal jealousy and war.

\section{TANZANIA: GENERAL EDUCATION SYSTEM}

Like many other African countries, the first schools in Tanzania commonly belonged to and operated under religious groups, therefore the number was very limited. 
Besides, only very few schools were established by the government. During Nyerere administration, these schools were nationalized and until today some of them are still run by the government. After independence, under the motto education for people, the government started to establish more schools.

Nowadays, children in Tanzania can start their education from very early age, nursery school, and continue with primary school (it is called Standard 7 in Tanzania). From this two basic education levels, pupils learns in Swahili except in English medium schools that offer English as language of instruction; the number of English medium schools is very limited and usually only limited in urban area. Graduating from primary school, they continue with secondary schools, Form 4 for two years and Form 6 also for two years; Form 4 is also called Ordinary Level School and Form 6 is called Advanced Level school. All secondary schools are supposed to use English as language of instructions.

\section{TANZANIA: HIGHER EDUCATION}

Since her independence, Tanzania has established more or less 40 higher institutions to date. The first higher institution was established in 1961 and was called Dar Es Salaam University College, a constituent (university) college of University of London. As an affiliation, Dar Es Salaam University College only catered one faculty, Faculty of Law, and received only 13 students. In 1963, Tanzania and two other Eastern Africa countries, Kenya and Uganda, signed a contract establishing harmonized higher education institution called University of East Africa (UEA) under an affiliation with University of London; University of Dar Es Salaam in Tanzania, Makerere University in Uganda, and University of Nairobi in Kenya. In 1970, UEA collapsed, and the three countries decided to nationalize and run the university in their own country. From 1970 to 2003, Tanzania added 4 more public universities, namely Sokoine University of Agriculture (SUA), Mzumbe University, Open University of Tanzania (OUT), and State University of Zanzibar; the establishment of private institutions was started in 1995 when liberalization of education received concern.

In its early year, these four universities only received few numbers of students due to financial problem where only financially capable family can afford higher education. The government than introduced cost-sharing fees that is supposed to enable low income family to send their children to university (Ishingoma, 2004). The cost sharing program has proven helpful and assisted those qualified student from poor family to enter university.

The burgeoning university in recent decades is without no reason. The yearn for higher education in Tanzania, especially graduates with significant degree were very much needed thus government made this urgency to allow establishment of public and private institutions. Education for people as it was echoed during Nyerere's presidency has manifested today. 
As in 2014, Tanzania has established more or less 50 universities. The number of public institutions is 18 and private ones are 32 (TCU, 2014). The burgeoning university across the country in the last 2 decades has enacted the government to establish a higher institution body that controls and manages all the universities called TCU (Tanzania Commission of Universities). As it was established on July 2005, TCU envisions an accessible, equitable and harmonized education system particularly in tertiary education level. The main role of TCU is to "recognize, approve, register and accredit Universities operating in Tanzania and local or foreign University level programs being offered by registered higher education institutions". As regulatory, advisory, and supportive institution, TCU builds centralized system of application process that screen eligibility of applicants based on the applicants' Form 6 result. In this manner, university receives students who are already approved by TCU, no universities are allowed to receive direct application (TCU, 2014). In other words, as newly established government's body, TCU regulates the students' intake of all higher institution in Tanzania. Before this establishment, students did not pass through TCU to enroll the university. Thus, only limited students with best quality were accepted by universities.

Along with TCU, Tanzanian government also established loan body to assist students' financial need called HESLB (Higher Education Students' Loans Board) in July 2005. The objective of HESLB is to assist students, who are already registered in TCU, with financial problem by offering students loan, and HESLB is also responsible to collect due loans from the previous beneficiaries (HESLB, 2014). The students receive loans on fortnight and/or monthly basis with varied amount based on the major taken by the student; the loan covers accommodation, stationary, meals, and department special need.

The existence of HESLB has widely opened opportunities for people to enroll universities. On one hand, HESLB provides opportunities for the underprivileged citizens to go to higher institution and gives the same opportunities for all citizens to receive loan. After HESLB was established, number of universities students has had increasing significantly due to the financial aid; before almost all department received less than 100 students. On the other hand, this massive intake of students does not correspond with the screening process; the enrollment is centralized through TCU's admission system and the students are graded based on their national exam result. As every citizen has equal rights for education therefore every citizen has the same opportunity to go to higher institution as long as s/he has passed Form 4 (for diploma and certificate) and Form 6 (for bachelor degree).

\section{ISSUES CHALLENGING HIGHER INSTITUTIONS}

\section{Market Demand}

Stakeholders are the most affected agent in the result of higher education. The last three years, the massive failure of university graduates fulfilling satisfied job demand is very low. Private companies complain on the inability of the fresh graduates to respond duty properly in workplace. Besides, best score shown in the academic 
transcript does not guarantee job performance. Academic performance is not accompanied by soft skill salient to workplace. Universities graduates possess limited skill to survive in workplace and they are not trained to execute day to day work. Hence, the fresh university graduates are the most unwanted employee at the job market. Another reason is] university graduates, according to many companies, like to demand higher salary which does not correspond to their job performance so it is a loss for the companies since the graduate unable to perform good job. University has created big labor force but does not prepare them with sufficient skills.

\section{Issues in Secondary Schools}

As in 2013 alone Tanzania claims to need as many as 5000 secondary teachers, it means that until recently, the influx number of secondary school graduates are in question. In the case of public schools, there are many cases reported that students move to other school in different regions because their former schools do not have adequate teachers to teach them, meaning only few in number and unqualified teachers. The reasons behind unavailability of teachers are due to poor facilities in rural area: covering accommodation, transportation, teaching materials, recreation, and salaries. This label in rural schools thus drives away teachers especially those with more qualified education. Hence, it is common that many teachers from rural area do not possess qualified teaching certificate such as certificate from Teacher College or university but secondary school graduates (mostly from Form 6). Lack of proper and well-educated teachers consequently produce low quality of secondary school graduates that affects university students' intake.

Accumulation of the problem revealed in 2013 where Tanzania suffered massive failure of Form 6 result with only about $40 \%$ of total students passed the national exam and left $60 \%$ of students in dire situation. It means that from the early stage, the university input is not very good. Almost every year, the top ten best schools belong to private schools, which means better facilities and better teacher qualification, that means only the-have have the opportunity to study in such school while the majority are studying in public school that offers lower school fees.

\section{Centralized system in higher education}

The centralized system established by TCU has badly affected higher institutions. Application for university is started around March and April. All applicants should submit their documents to TCU, either by post or online system; both systems are disadvantage because mail system can take very long and online system requires computer whereas the majority of Tanzania is not computer literate even more internet literate. After the applications are reviewed, TCU allocates students to appointed university based on the students' choice and students' final exam score (through NACTE). However, many students complain of being displaced either university or program of not their choice. In the screening process, universities are not involved and all applicants who own certificate of Form VI eligible to apply or those who pass NACTE exam. In this case, university has no authority over their prospective students before TCU approves them. 


\section{Loan Board System}

Loan board system is meant to assist financially unable students to pursue higher education. However, loan board fails to deliver the purpose because many students go to university for the sake of loan. It means that many prospective students purposefully apply for university to get the loan and use the money for other business instead of spending it for academic purpose. As loan board gives priority to particular faculties, the numbers of applicants are numerous. Therefore there is stereotype, especially for those from prioritized faculty for loan, that many students are suspected going to university in order to get the loan and degree without studying. Even though it is very presumptive, it creates new trend among students. There are three types of students who receive the loan. First is entrepreneur who uses the money for business but still regard studying as important. Second is students who spend the money for academic purpose, and the third are those who do not bother to study but spend the money for either business or luxuries.

\section{Human capital}

Untrained staffs and incompetent lecturers become another issue. The yearn for more lecturers with doctoral degree is as salient as trained staff. Some universities fall under the threat of letting assistant tutor with bachelor degree to teach in undergraduate program; the regulation calls for at least master degree as assistant lecturer to teach undergraduate program. However, lecturers with $\mathrm{PhD}$ or even professorship do not guarantee better teaching and learning because many are claimed busy with their researches and consultation job.

As observed by Kuhanga (2006), universities also lack of trained and adequate number of non-teaching staff, which means daily operation of the universities might be hampered. Most universities do not pay much attention to non-teaching staffs. There are many people take the office but are not qualified to carry on the job, like quality assurance, librarian, human resources, even secretary.

\section{Inadequate facilities}

Issues of facilities spread across Tanzania. Physical facilities like classroom and public space for discussion are beyond qualified. Big classroom accommodating at least 300 students are common sight and students taking chairs from classroom for discussion at the park are also common. Worse of all, more often than not, students need to look for chairs before coming to class because number of chairs are insufficient. These are simple matter but hamper the teaching-learning process not to mention lecturer's class management will be very low. Library as the learning centre for students is also poorly managed. Untrained staff and insufficient number of books for students have created major problem of information sharing. The limited number collections, not to mention journals and academic writing, have forced students to 'queue' to read the book. Students' workstation with computers and internet connection is scarce. This result in students' poor performance in operating computer, even many do not know how; students might be familiar with 
internet but limited to chatting room in their smart phone but computer literacy remains low.

7. Low academic culture

Academic culture is the heart of higher institution. All the academic activities like lecture, reading, research, discussion are among the cultures nurtured in universities. Universities atmosphere does not accommodate this need as it is related to the available facilities offered to students. Discussion room and library are very limited hampering students to stay and borrow book for further study.

On important issue which seems forgotten and neglected is plagiarism. Students' researches are far from original and analytical. The majority likes to copy and paste from other students' previous research and internet. This is a catastrophe in academic world, originality is very important as it initiates creativity and analytical mind. 'Talk and chalk' where lecturers are talking and students are listening are common sight where students reproduce the same narrative as what the lecturers have taught them.

\section{Language gap}

Based on government regulation, medium of instruction in school is English. However, the majority of standard schools (primary education) use Swahili while the secondary schools (form I-VI) have started using English although not fully English; students with good English command mostly graduate from elite private schools where English is the language of instruction. Higher institution is strongly required English for the language of instruction. It implies that the switching code from Swahili to English is not easy for many students, moreover English is third Language; Tanzania has about 120 local languages and uses Swahili as national language and majority of students use Swahili and mother tongue for daily communication. Thus students find it difficult to understand lecturers and reading requirements. Therefore, in the university level, the understanding of the material is lower because their English is insufficient. Or, even though they speak English, their written English is very poor.

\section{POSSIBLE SOLUTIONS}

1. Independent university

As mentioned above, each higher institution in Tanzania is not allowed to receive students directly but through TCU. This centralized system gives disadvantages to the institution because each institution cannot create good standard as well as varied academic calendar; the recent case of students intake in 2014/2015 academic year, one private university has already started classes while TCU has still continued sending students to the particular university, it results in chaotic academic schedule and late arrivals of students to start studying. Besides, the disparity between schools concerning national exam results is very high. For example: students have the same result for final exam, it does not mean they acquire and learn the same thing. Therefore if an institution requires an entrance test for each prospective 
student, the result can tell the IQ and EQ of prospective students (IQ is no longer sole requirement for success but EQ). In this manner, the entrance test does not only cover intellectual and academic ability but also psychological aspect so the decision to place student in certain program/department is not solely based on intellectual and academic result. The issue of manipulation in exam result is another problem. By applying entrance test, university can established a more serious standard because the test result is pure students' work. Also, it will give the institution more freedom to be a more qualified university that in the long run can boost the institution's fame. By this, survival of the fittest applies that institution with good qualification will survive where students is more preferable to go to. With entrance test, slowly the university can build a name and set a standard for its desirable students (the counter argument for this is that it will only give access to smart as well as well - off prospective students).

On par with university entrance test, giving institutions freedom means the institutions are also freer in determining tuition fees based on students financial ability or students score in the test. One possible setting is to ask well-off students to pay higher fee and reduce the tuition fee for the low income students. The institution can also provide financial support for those who perform well. This thus requires a good management in the institution itself.

\section{Integrated body between education beneficiaries}

The education beneficiaries here refer to not only students and parents but also the stakeholders, and university staffs. Collaboration between parents, institutions and stakeholders is important to determine the quality of the institution. Parents are involved in the policy making because they have sent their children to university with expectation of better life therefore parents as one of the financial source should also be included in the policy making. As the stakeholders here covers to the related parties who employ the university graduates, these stakeholders are those who know better the trend in the job market so institution can collaborate to establish suitable and qualified graduate based on the job market demand. Designing curriculum based on the need of the job market will prepare students better.

The establishment of the board consisting of parents, stakeholders and institutions will benefit the university not only in its education quality but also institution management. The mismanagement of the institution can be minimized as the board overlooks and supervise the management, so transparency becomes solution.

\section{Emphasis on learning process}

University means "an institution which offers a level of education and training that lead to intermediate and full academic or professional qualifications and competence, namely certificate, diplomas, and degrees" (The Universities Acts, 2005). In other word, university is the institution that offers and prepares students real life skills, especially in job market. By the same token, the process of producing 
qualified and suitable candidates must be included in the curriculum whereby process is prominent than result.

The current situation across Tanzania, the old paradigm that holding degrees or certificate ensures job security still persists. Hence, it is not uncommon for students to rely on and struggle hard to be eligible to sit at final exam neglecting, regular, if not, daily classes that offer more critical and creative basis than memorizing notes. The learning process lies on the regular class where students and lecturers interact in scholarly discussion through case studies, assignments, and/or quizzes emphasizing on the critical and analytical skills of the students. This will lead to students' self-reliance, building students responsibility and confidence that they are able and capable. Emphasizing on practice instead of theoretical is also important as it gives students more real model of the real world.

4. Improve the facilities

Big class results in insufficient learning outcome. Dividing classes into small classes consisting of 30-40 students will give benefit to both students and lecturers. Lectures supervision becomes easier and class discussion is more preferable. By giving each lecturer small classes, 3-5 classes per week, it will minimize lecturers' overburdened teaching load, not to mention the exhaustion of administrative work. By this, it reduces lecturers' burden of collectively correcting the exam at once. By this notion, the institution should increase the number of their teaching staff. If the institution cannot afford to hire more teaching staff, it would be wise to 'slow down' the students' intake; it means TCU as the monitoring body should evaluate each institution, especially its capacity to accommodate students.

Small classes also helps lecturer to carefully read students' papers, critically teach students to logically and critically build up an argument. Besides, it gives chance lecturers to monitor students' individual progress and assess them accordingly. By this, the assessment and evaluation reflect not only students' academic life but also its application by giving more analytical questions (students papers if it is carefully taught will help students to be more critical because they are required to read and argue logically and responsibly).

Academic life is constituted by reading culture. Availabilities of books and internet facilities are beneficial to both support students' academic life and enhance students' knowledge. As saying goes, books are the windows of the world, it applies to university students. Library is suggested to provide photocopy machine as well as provides more copies of the books. As the number of students sometimes outnumbers books availability in the library, it hinders the learning process. Workstation for students with computer and internet connection should be improved in number especially to accommodate the majority of students who do not possess computer to learn and use computer by themselves. Today is a digital era, if students fail to operate computer on basic level, they are not ready to enter job market as many companies requires high level of computer literacy. 
5. Swahili as the language of instruction in classroom English as language of command in university body is needed to be reviewed. The original idea and aim of using English, apart as the legacy of British system, is to prepare Tanzanians for global market. Hence Tanzania adopts English as means of language in school started from the high school. However, the result shows that the majority, especially those attending public school, do not perform well in using English. The case is even worse as some lecturers, despite the regulation to use English in classroom, use Swahili. Compare to other commonwealth countries, English in Tanzania is not as good as other countries. Students' understanding on English vocabularies is limited and sentence construction is mostly incorrect even though students have 'used' English since high school. Knowing this, the use of Swahili on schools, especially in higher education is much recommended and put English as foreign language and as subject. As Swahili is widely used and understood across the country, the knowledge transfer in school will be easier and better.

\section{CONCLUSION}

The influx of students intake in the past decade and decrease of students' intake recently reflects the situation of higher education. Financial problems of prospective students and failure of national exams orchestrated the problem. The big number of unemployment rate of university graduates contributes to skepticism towards university's credibility to improve life and be self-reliant.

The issue concerning higher institution is complicated referring the fact that most of the higher institutions are new and Tanzania is still in on-going process to develop her identity. The small steps to fill in the gap are to start slowing down enrolment and to nurture small class with better academic and accommodative environment to study. Tanzania has to go through such long process to acquire quality higher education especially with the current situation. Small changes started from university can be the stepping stone towards quality education.

\section{REFERENCES}

Acemah, H. (September 24, 2013). What is the role of universities in Africa?. The Citizen, 21

African graduate skills 'inadequate'. (January 23, 2011). Sunday News, 13

Awiti, A. O. (August 23-29, 2014). Why EA's varsity graduates are ill-equipped for the global job market. The EasternAfrican, 34-35

Barozi, S. (September 25, 2011). Massive decline in English knack for pupils, teachers. The Guardian on Sunday, 6

Britto, R. (April 10, 2012). Plagiarism shouldn't be tolerated. The Citizen, 8

-------. (January 17, 2012). Students must strive to be creative. The Citizen, 8

Freire, P. (1999). Pedagogy of the Oppressed. Ramos, M. B. (Tran). New York: Continuum.

Hass, N. (August 23-29, 2014). The college you attend has a bearing on future income. The EasternAfrican, 35 
Higher Education Students' Loan Board. Retrieved December 20, 2014 < http://www.heslb.go.tz/ >

Ishengoma, J. (2004). Cost Sharing in Higher Education in Tanzania: Fact or Fiction. Journal of Higher Education in Africa, 2(2), 101-34

James, B. (December 11, 2011). Vanishing reading culture may turn Tanzania into a nation of illiterates. The Citizen on Sunday, 9

Kalokola, S. (June 21, 2011). Where are the English speaking Tanzanians?. The Citizen

Kazeri, B. (January 14, 2014). The unforgettable fifteen years of building an institution of academic excellency and repute. The Guardian, 19

Kazoka, L. (May 9, 2013). UDSM: improving students' welfare is top on agenda. Daily News

Kiruku, A. (November 3-9, 2013). EA forum pledges to harmonize higher education in the region. The Guardian on Sunday, 4

------------. University enrolment 'very low in EAC countries. The Guardian, 4

Kitabu, G. (September 6, 2011). How to reverse decline in reading culture among Tanzanians. The Guardian, 7

Major, Thenjiwe \& Mulvihill, Thalia M. (October 2009). "Julius Nyerere (1922-1999), an African Philosopher, Re-envisions Teacher Education to Escape Colonialism" in New Proposals: Journal of Marxism and Interdisciplinary Inquiry.Vol. 3, No. 1 Pp. 15-22

Massawe, A. (February 23, 2013). Here is how we can curb academic copy-cat trend. The Citizen on Sunday, 12

Mbiro, M. (June 19, 2013). Tanzania still trails behind in higher education students' enrolment. Sunday News, 17

Mchome, E. (December 28, 2010). Where lack of lecturers bites hard. The Citizen, 17 17

Morisset, J. \& Lee, S. (February 22, 2012). Tanzania: Buildings bridges through education and small business. World Bank. Retrieved October 22, 2014 <http://blogs.worldbank.org/africacan/tanzania-building-bridges-througheducation-and-small-businesses>

Moses, H. (July 3, 2011). Is education: enslaving or empowering Africa?. The Citizen, 12

Mtei, D. (August 8-14, 2013). Varsities short of 30,000 students. Daily News, 9

Mungai, C. \& Mwaura, P. (January 11-17, 2014). High enrolment in EAC universities pushes down quality of learning. The EastAfrican

Mushi, D. (June 2, 2013). What has gone wrong in Catholic seminaries?. Sunday News, 11

Mwachang'a, D. (October 22, 2013). HESLB reopens loan application. The Guardian, 1-2

Mwapachu, J. (June 9, 2013). Africa's competitiveness: what role for our universities?. The Citizen on Sunday 
------------. (June 16, 2013). The African university - tests for global dynamics. The Citizen on Sunday

Nkwame, M. (October 10, 2010). Universities qualified lecturers. Sunday News

Nyerere, K. J. (1967). Education for self-reliance. Dar es Salaam : The Government Printer

Nyirenda, D. M. (November 8, 2011). Plagiarism and its effect on education. The Guardian, 8

--------. (October 22, 2013). We must curb graft in education sector. The Guardian, 7

Samoff, J., \& Carrol, B. (2003, July). From manpower planning to the knowledge era: World Bank policies on higher education in Africa. UNESCO Forum on Higher Education, Research and Knowledge, Division of Higher Education, UNESCO

Sengiyumva, G. (December 9, 2010). Universities have increased in number but qualitatively have long way to go. Daily News

Tambwe, M. (August 7, 2011). Plagiarism in higher learning institutions high. Sunday News, 7

$\begin{array}{lllll}\text { Tanzania } & \text { Overview. } & \text { Retrieved }\end{array}$ <http://www.worldbank.org/en/country/ tanzania/ overview>

Tanzania Commission for University. Retrieved December 20, 2014 < http://www.tcu.go.tz/ >

TCU is under right performance. (June 10, 2013). Sunday News, IV

The Universities Act. (2005). The Universities Act. Tanzania

Ubwani, Z. (October 5, 2012). University enrolment rising steadily. The Citizen, 23

Wanasolo, I. (March 12, 2013). Getting varsity degree you won't use it senseless. The Citizen, 9

Varghese, N. V. (2006). Growth and expansion of private higher education in Africa. Growth and expansion of private higher education in Africa, 27-54 